\title{
MARKET POWER ANALYSIS IN MONGOLIAN WHEAT INDUSTRY
}

\author{
Erdenebat Purev ${ }^{1}$, Purev Byamba ${ }^{2}$ \\ ${ }^{1}$ Otgontenger University, Bayanzurkh District, Peace Ave. Jukov street, Ulaanbaatar, Mongolia \\ ${ }^{2}$ Mongolian University of Life Sciences, Khan-Uul District, Zaisan, Ulaanbaatar, Mongolia \\ 1erdenebat@otgontenger.edu.mn \\ 2prv03@yahoo.com
}

\begin{abstract}
Mongolia has been in transition from a planned economy to a market economy for more than 20 years. In many sectors of the economy, it is necessary to define which market mechanisms exist. Grain occupies important economic sector in Mongolian economy. The current state of the wheat market has been studied based on NEIO research methods. In this study, the data for years from 2000 to 2017 and from 2007 to 2017 about wheat and wheat seed sector were taken through 6 indicators. We estimated the supply and demand functions for wheat and wheat seed. Using these functions, we defined market behavior, cost function, price elasticities, and market equilibrium. The capacity setting for product prices of wheat producers is weak, and this market is likely free-style competition.
\end{abstract}

Keywords: NEIO, wheat, market power, market equilibrium, market distortion

\section{INTRODUCTION}

Wheat is considered as one of the strategically important products in Mongolia. Due to cumulative impact of recent favorable weather conditions (except 2015 and 2017), state policy support, including "Atar ${ }^{1}$ III" campaign, diligence and efforts of producers has shown a tendency of recovery and development since 2008 in wheat production. Regardless of certain progresses in the cereals sector, there has still existed numerous pressing issues in state policy, technology, economy and management. During the time period from the beginning, there has been considerable disputes on wheat prices, which rises to become focus discussion every autumn. Wheat prices are fixed in accordance with tripartite agreement between flour producers, grain growers and the government. Consequently, grain-growers receive 50.000 to 100.000 tugrugs (MNT) subsidies from the government. Researches and analysis of such price fixing practices is essential. To solve this dispute accordingly, we have to conduct a comprehensive and detailed research on wheat market characteristics, state policy and weather factor impacts. ${ }^{1}$

\section{Weather conditions}

Irrigation system is not practical in Mongolia. Therefore, wheat production is largely dependent on climate conditions every year.

In 2015, Government of Russian Federation passed a resolution to determine borders for crop zones throughout country territories. According to this decision, weather conditions will be defined through Hydrothermal Coefficient (HC), utilizing precipitations, temperatures in May-August, and August-September. By virtue of geographical location, we

$1 \quad$ reclaim virgin land 
can employ this method in Mongolia to its adaptable extent. Central zone weather conditions are defined in accordance with 2000-2017 weather parameters. The HC will be defined as follows:

Vegetation period HC: HC $=\left(\sum \mathrm{PV}-\mathrm{VIII}\right) /\left(0.1 \sum\right.$ TV-VIII $)$ Harvesting period HC: $\mathrm{MHC}=\left(\sum\right.$ PVIII-IX $) /\left(0.1 \sum\right.$ TVIII-IX $)$ ${ }^{1}$ reclaim virgin land

Table 1.The Central Region Meteorological Conditions

\begin{tabular}{lcc}
\hline HC & Weather Condition & Probability \\
$1.6<$ & Over moisture & $0.0 \%$ \\
$1.6-1.3$ & Moisture & $12.5 \%$ \\
$1.3-1$ & insufficient moisture & $43.8 \%$ \\
$1-0.7$ & Drought & $37.5 \%$ \\
$0.7-0.4$ & severe drought & $6.2 \%$ \\
$<0.4$ & Dry & $0.0 \%$ \\
\hline
\end{tabular}

Table 1 shows that climate condition of Mongolian land with a significant risk to farming. The yield function of wheat per hectare was determined using the relevant data for 2007-2018.

Table 2. The wheat yield function

\begin{tabular}{lcccccc}
\hline & Intercept & HC & HCF & $\mathrm{GP}_{2008}$ & $\mathrm{t}$ & $\mathrm{R} 2$ \\
\hline Coefficients & 0.429 & 1.975 & -0.972 & 0.175 & -0.018 & \\
\hline $\mathrm{t}$ stat & 1.183 & 3.462 & -2.222 & 0.676 & -0.589 & 0.733 \\
\hline
\end{tabular}

Whereas, the variables GP2008 and t are the indicators of the government's 2008 year agricultural development policy and technical progress, respectively. Favorable weather conditions during wheat growing period and government policy support have had a significant positive impact on wheat yields. However, this relationship shows that unfavorable weather conditions during harvesting and the backwardness of agricultural technology negatively affect the growth of wheat yields. As a result of these factors, the average yield per hectare of wheat is likely to be 1.59 tons / ha.

\section{Method of Investigation}

Wheat market mechanism is created during last 20 years. Effectiveness of policy regulations depends on compliance with specific market parameters. Production and market related research was made on the basis of New Empirical Industrial Organization (NEIO) method. Based on the works of researchers Bresnahan,T.F. (1981,1982), Appelbaum,E. (1982), O’Donnell,C.J. et al (2004), and Schroeter,J.R. (1988), we used the following model for this study.

\section{Demand function}

$Q=a_{0}+a_{1} P+a_{2} Y+a_{3} P S+a_{4} S+\varepsilon$

Where: $\mathrm{Q}$ is quantity of product, $\mathrm{P}$-product price

S-price of substitutes, Y-consumer's income.

Demand function represent consumer's market conditions.

Marginal cost function

$M C=b_{0}+b_{1} Q+b_{2} M+b_{3} N+\eta$
Whereas: MC-marginal costs, Q-quantity of product, M-price of relevant production factors, $\mathrm{N}$-macroeconomic or weather conditions factors.

Supply function represents producers' market conditions.

Using the demand function, determined the marginal revenue function as follows:

$$
M R=P+Q \frac{\partial P}{\partial Q}=P+\frac{Q}{a_{1}+a_{3} S}
$$

Marginal revenue as perceived by farm, stating market power, will be as follows:

$$
P M R=\lambda\left(P+\frac{Q}{a_{1}+a_{3} S}\right)+(1-\lambda) P=P+\lambda \frac{Q}{a_{1}+a_{3} S}, 0 \leq
$$

Using $\mathrm{PMR}=\mathrm{MC}$ equality conditions we will derive supply function.

Supply function

$$
P=\lambda\left(-Q_{1}\right)+b_{0}+b_{1} Q+b_{2} M+b_{3} N+\gamma, Q_{1}=\frac{Q}{a_{1}+a_{3} S}
$$

Whereas, $\lambda$ in (4) is measure, expressing degree of market power. In case of free competition $\lambda=0$ and $\lambda=1$ in the case monopoly market. In a case of oligopoly market $\lambda \approx 0.5$, and in a case of monopolistic competition this measure will be $0<\lambda<0.5$. Using the cost function, we will similarly determine degree of monopsony market power.

\section{Empirical models and estimation results}

This study is a sector-level research rather than a farm level one.

\section{Food wheat market}

\section{Data}

In this study, the data of the wheat sector is taken under 6 indicators with covering period from 2000 to 2017.

The wheat market study was carried out using the methodology described above.

The data indicators: Pwheat, Qwheat-wheat price, quantity, Pwrimport-imported wheat price, Rexchrate-MNT to dollars real rate of exchange, HC-hydro thermal coefficient, VAcropcrop sector value added. T-Time trend, Dummy-policy impact accordingly. The price was expressed at 2010 constant prices.

Table 3. Wheat demand model

\begin{tabular}{lccccccc}
\hline Demand & $\mathrm{C}$ & Pwheat & Pimport & PwhPimp & Vacrop & Dummy & $\mathrm{T}$ \\
\hline Qwheat & 1016.1990 & -2.6984 & -2.3669 & 0.0098 & -0.0004 & 438.8854 & -30.4320 \\
$\mathrm{t}$ & 3.2601 & -2.9372 & -2.6711 & 3.2697 & -0.7429 & 5.9160 & -3.4401 \\
\hline & $\mathrm{R} 2$ & 0.872 & $\begin{array}{c}\text { Akaike } \\
\text { crit }\end{array}$ & 11.344 & DW & 2.891 & \\
\hline
\end{tabular}

Wheat demand is price Inelastic $(\mathrm{Ed}=-0.901)$ 
Table 4. Wheat Supply model

\begin{tabular}{lccccccc}
\hline & Qwheat & Q1 & rexchrate & Vacrop & HTK & Dummy & T \\
\hline Pwheat & 0.5071 & 0.0163 & 0.0803 & 0.0013 & -126.7378 & -140.9505 & 10.4516 \\
$\mathrm{t}$ & 2.1609 & 0.6824 & 6.8023 & 4.1373 & -1.9305 & -1.7252 & 1.7427 \\
\hline & R2 & 0.620 & $\begin{array}{c}\text { Akaike } \\
\text { crit }\end{array}$ & - & DW & 2.095 & \\
& & & & & & & \\
\hline
\end{tabular}

Statistical inference of estimated demand and supply functions are quite significant.

Degree of market power $(\lambda=0.016)$ is perfect competitive.

Wheat supply is price elastic $(E s=2.922)$

Determined the marginal and average cost functions by using the estimated supply function.

Table 5. Marginal cost function

\begin{tabular}{cccccccc}
\hline & Qwheat & Q1 & rexchrate & Vacrop & HTK & Dummy & T \\
\hline Pwheat & 0.5071 & 0.0163 & 0.0803 & 0.0013 & -126.7378 & -140.9505 & 10.4516 \\
$\mathrm{t}$ & 2.1609 & 0.6824 & 6.8023 & 4.1373 & -1.9305 & -1.7252 & 1.7427 \\
\hline & R2 & 0.620 & $\begin{array}{c}\text { Akaike } \\
\text { crit }\end{array}$ & 10.930 & DW & 2.095 & \\
\hline
\end{tabular}

Table 6. Average cost function

\begin{tabular}{lccccccc}
\hline & Qwheat & Q1 & rexchrate & Vacrop & HTK & Dummy & T \\
\hline Pwheat & 0.2536 & 0.0163 & 0.0803 & 0.0013 & -126.7378 & -140.9505 & 10.4516 \\
$\mathrm{t}$ & 2.1609 & 0.6824 & 6.8023 & 4.1373 & -1.9305 & -1.7252 & 1.7427 \\
\hline & R2 & 0.620 & $\begin{array}{c}\text { Akaike } \\
\text { crit }\end{array}$ & 10.930 & DW & 2.095 & \\
\hline
\end{tabular}

Wheat market equilibrium is determined using the estimated demand and supply functions. Wheat market equilibrium is different each year. Equilibrium prices are determined on comparative constant (at 2010) and annual nominal prices.

Table 7. Wheat market equilibrium

\begin{tabular}{lccc}
\hline & Q & Pconst & Pnominal \\
\hline 2007 & 94.7 & 309.1 & 208.2 \\
2008 & 381.3 & 502.9 & 411.5 \\
2009 & 407.6 & 467.4 & 389.4 \\
2010 & 462.7 & 357.4 & 357.4 \\
2011 & 487.2 & 311.6 & 358.7 \\
2012 & 447.5 & 239.8 & 311.4 \\
2013 & 320.9 & 287.3 & 383.9 \\
2014 & 412.7 & 425.4 & 610.7 \\
2015 & 268.9 & 397.3 & 580.2 \\
2016 & 410.8 & 382.9 & 571.6 \\
2017 & 247.8 & 402.2 & 648.5 \\
\hline
\end{tabular}

\section{Measuring the market distortion}

In a free market, the prices of individual commodities are set by the laws of supply and demand. When the price of a commodity does not seem to follow the laws of supply and demand, it is sometimes referred to as a cost distortion, price distortion or market distortions.
Market distortion is an economic scenario that occurs when there is an intervention in a given market by a governing body. Market distortions create market failures. Market distortions are often a byproduct of government policies that aim to protect and raise the general well-being of all market participants. Almost all types of taxes and subsidies, but specially excise or ad valorem taxes or subsidies, can cause a market distortion. In addition, asymmetric information, uncertainty among market participants, or any policy or action that restricts information critical to the market can cause a market distortion. In the case of distorted market conditions, the social or economic price of goods will be determined as follows:

$$
\begin{aligned}
& \mathrm{P}^{\text {social }}=\mathrm{W}^{\mathrm{sPm}} /(1-\mathrm{s})+\mathrm{W}^{\mathrm{d} \mathrm{Pm}}(1+\mathrm{t}) \\
& W^{s}=\frac{\varepsilon^{s}}{\left(\varepsilon^{s}-\varepsilon^{d} \frac{Q^{d}}{Q^{s}}\right)}, W^{d}=-\frac{\varepsilon^{d} \frac{Q^{d}}{Q^{s}}}{\left(\varepsilon^{s}-\varepsilon^{d} \frac{Q^{d}}{Q^{s}}\right)}
\end{aligned}
$$

Where, $\mathrm{Pm}=$ market price, $\mathrm{s}=$ subsidy, $\mathrm{t}=\mathrm{tax}, \mathrm{Ws}, \mathrm{Wd}=$ supply and demand weights.

The following table shows the 2010 and 2017 years wheat social prices.

\begin{tabular}{|c|c|c|c|c|c|c|c|c|c|}
\hline \multirow{2}{*}{$\begin{array}{l}\mathrm{e}_{\mathrm{d}}= \\
\mathrm{D}:\end{array}$} & \multicolumn{2}{|c|}{-0.734} & $\mathrm{e}_{\mathrm{s}}=$ & \multirow{3}{*}{$\begin{array}{c}2.922 \\
\mathrm{~S}:\end{array}$} & \multicolumn{4}{|c|}{$\mathrm{t}=$} & \multirow{3}{*}{0.1749} \\
\hline & \multicolumn{3}{|c|}{$q=1150.802-2.6984 p$} & & \multicolumn{4}{|c|}{$q=-234.998+1.972 p$} & \\
\hline 2010 & $P_{\text {constgnt }}$ & $P_{\text {nominal }}$ & & & & $\mathrm{p}_{1}=$ & $\mathrm{P}_{\mathrm{d}}$ & $\mathrm{P}_{\mathrm{s}}$ & \\
\hline $\mathrm{p}=$ & 285.8 & 285.8 & $\mathrm{q}=$ & 460.2 & & 335.8 & 300.09 & 346.4 & \\
\hline $\mathrm{p}_{1}=$ & 335.8 & 335.8 & $\mathrm{qd}=$ & 244.7 & $\mathrm{qs}=$ & 427.2 & & & \\
\hline \multirow[t]{2}{*}{ Psocial $=$} & 340.6 & 340.6 & $\mathrm{wd}=$ & 0.126 & $\mathrm{ws}=$ & 0.874 & & 1 & \\
\hline & & & & & & $t=$ & 0.05 & $\mathrm{~s}=$ & 0.0824 \\
\hline 2017 & $\mathrm{P}_{\text {constant }}$ & $\mathrm{P}_{\text {nominal }}$ & & & & $\mathrm{p}_{1}=$ & $\mathrm{P}_{\mathrm{d}}$ & $\mathrm{P}_{\mathrm{s}}$ & \\
\hline $\mathrm{p}=$ & 376.2 & 606.4 & $\mathrm{q}=$ & 158.6 & & 407.2 & 395.0 & 410.0 & \\
\hline $\mathrm{p}_{1}=$ & 407.2 & 656.4 & $\mathrm{qd}=$ & 52.0 & $\mathrm{qs}=$ & 568.0 & & & \\
\hline Psocial $=$ & 409.7 & 660.4 & $\mathrm{wd}=$ & 0.022 & ws $=$ & 0.978 & & 1 & \\
\hline
\end{tabular}

Table 8. Wheat social price

As noted here, the distorted wheat price as $\mathrm{p} 1$ and $\mathrm{p}$ is wheat market price.

Wheat prices because of market distortion is increased by $17,5 \%$ in 2010 and $8.2 \%$ in 2017.

Demand and supply prices for wheat are changing due to taxes and subsidies, but the social price of wheat is between these two prices. For example, the condition Pd $<$ Psocial $<$ Ps is satisfied. Taxes and subsidies have had a large effect on supply prices and a small effect on demand prices.

The social price of wheat at 2010 constant prices would be 340.6 in 2010 and 409.7 thousand MNT in 2017.

\section{Wheat seed market}

Plant seed policy, management and financing play crucial role for the restoration of the crop sector. Seeds are the primary basis for human sustenance. Improving crops and providing producers with high-quality seeds and plant material of breeding varieties is necessary to improve the quality of crop production and solve increasingly serious environmental problems. 
The state is paying great attention to improving the quality and supply of seed plants and improving the seed farming system, but there is no proper outcome. Farmers and companies are uncontrolled cultivation of different varieties, because seed and varieties policy was not functional since the 1990s. The Crop Production Supporting Fund (CPSF) is responsible for providing farmers with seeds and inputs. However, the fund has provided only about $15 \%$ of the expected seed. The remaining portion of the seed is provided with farmers own produced and imported seeds.

\section{Data}

The wheat seed market study was carried out using the methodology described above.

Wheat seed indicators are: Pwheat, Qwheat-wheat seed price, seed quantity, Pwrimport-imported wheat price, Vcropagriculture sector wage income, time trend $\mathrm{T}$-innovation influence, Dummy-policy impact factor.

Wheat seed demand and supply model

\section{Results of empirical model}

Table 9. Demand model

\begin{tabular}{clllllll}
\hline Intercept & $\mathrm{P}$ & Pimp & P*Pimp Vacrop Dummy & $\begin{array}{l}\mathrm{R} \\
\text { square }\end{array}$ & Fsign \\
\hline Qd= 10193.937 & -22.6138 & -34.3820 & 0.0516 & 0.0601 & 3256.2340 & & \\
\hline Tstat 0.6780 & -0.8605 & -0.9284 & 0.7537 & 2.6070 & 1.7210 & 0.7719 & 0.1035 \\
\hline
\end{tabular}

Price elasticity of Demand: $\mathrm{Ed}=-0.353$

Table 10. Supply model

\begin{tabular}{lcccccc}
\hline & Intercept & $\mathrm{Q} 1$ & $\mathrm{Q}$ & $\mathrm{T}$ & $\mathrm{R}$ square & Fsign \\
\hline $\mathrm{P}=$ & 703.3565 & 0.0103 & 0.0095 & -37.7435 & & \\
\hline Tstat & 14.9164 & 1.1601 & 1.9543 & -7.1211 & 0.9029 & 0.0006 \\
\hline
\end{tabular}

Wheat seed supply is high price elastic $(E s=8.686)$. Degree of seed market power $(\lambda=0.01)$ is also perfect competitive.

Table 11. Seed marginal cost function

\begin{tabular}{lccccc}
\hline & Intercept & $\mathrm{Q}$ & $\mathrm{T}$ & $\mathrm{R}$ square & Fsign \\
\hline $\mathrm{MC}=$ & 703.3565 & 0.0095 & -37.7435 & & \\
\hline Tstat & 14.9164 & 1.9543 & -7.1211 & 0.9029 & 0.0006 \\
\hline
\end{tabular}

Table 12. Seed marginal cost function

\begin{tabular}{lccccc}
\hline & Intercept & $\mathrm{Q}$ & $\mathrm{T}$ & $\mathrm{R}$ square & Fsign \\
\hline $\mathrm{AC}=$ & 703.3565 & 0.005 & -37.7435 & & \\
\hline Tstat & 14.9164 & 1.9543 & -7.1211 & 0.9029 & 0.0006 \\
\hline
\end{tabular}

Statistical significance of these models are good enough. Using these functions, the seed market equilibrium was determined. Market equilibrium varies annually due to internal and external factors. Statistical significance of these models are good enough.

Using these functions, the seed market equilibrium was determined. Market equilibrium varies annually due to internal and external factors.
Table 13. Wheat seed market equilibrium

\begin{tabular}{lccc}
\hline & $\mathrm{Q}^{1}$ & Pconst & Pnom \\
\hline 2007 & 7139.2 & 780.7 & 525.9 \\
2008 & 11092.0 & 736.5 & 602.6 \\
2009 & 12628.0 & 782.9 & 652.3 \\
2010 & 6722.6 & 660.6 & 660.6 \\
2011 & 3808.9 & 595.5 & 685.5 \\
2012 & 2307.9 & 539.6 & 700.6 \\
2013 & 2548.9 & 497.1 & 664.2 \\
2014 & 6089.5 & 545.5 & 783.1 \\
2015 & 6473.3 & 467.8 & 683.2 \\
2016 & 10918.2 & 492.6 & 735.4 \\
2017 & 9036.9 & 426.1 & 687.0 \\
\hline
\end{tabular}

$\mathrm{Q}^{1}$ :Crop Production Supporting Fund Seed's Supply

The market equilibrium price was determined at constant prices in 2010 and each year current prices.

For instance, the current price of wheat seed is $525.9-783.1$ thousand MNT and at 2010 constant prices is 426.1- 780.7 thousand MNT.

The annual average consumption of wheat in Mongolia is 320-330 thousand tons. Average annual wheat seed required is approximately 50 thousand tons. The average renewal wheat seed per year is about 10 thousand tons. This study demonstrates that only $59.2 \%$ of the demand for this seed renewal is met. Wheat seed demand directly related to total wheat production.

\section{RESULTS AND DISCUSSION}

The research on wheat and wheat seed markets was carried out using the NEIO method.

Using estimated demand and supply models defined market structure, market equilibrium, demand and supply price elasticities. A free competition mechanism is functioning for food and seed wheat market $(\lambda=0.016$ and $\lambda=0.0103)$. The price elasticity of demand for food and seed wheat is low, while the price elasticity of supply is high.

The reason for this is the backwardness of wheat production technology.

In a free market, the prices of individual commodities are set by the laws of supply and demand.

Market distortion is an economic scenario that occurs when there is an intervention in a given market by a government policy.

The impact of taxes and subsidies on the market equilibrium was determined in 2010 and 2017.

Wheat prices, because of market distortion, is increased by $17.5 \%$ in 2010 and $8.2 \%$ in 2017 relatively. Taxes and subsidies have had a large effect on supply prices and a small effect on demand prices.

The profitability of wheat depends on seed quality, technology and production efficiency.

Average annual wheat seed consumption in Mongolia is around 50 thousand tons. Seeds need to be renewed every 
4-5 years. Therefore, the elite and reproductive annual seed demand is about 10 thousand tons.

IPAS produces 350-400 tons of elite seeds per year. Therefore, seed multiplication centers should be established in the central, western and eastern regions of agriculture.

\section{REFERENCES}

Aguirregabiria,V. (2019): Empirical E Industrial Organization: Models, Methods, and Applications

Appelbaum,E., (1982):The estimation of the degree of oligopoly power

Bresnahan, Timothy F. and Peter C. Reiss (1991): "Entry and Competition in Concentrated Markets." Journal of Political Economy 99 (5):pp. 977-1009. URL

Bresnahan, T.F. (1989): "Empirical Studies of Industries with Market Power", in Schmalensee, R. and Willig, R. (eds), Handbook of Industrial Organization, Vol. 2, chapter 17, 1011-1057.

Bresnahan,T.F. (1982): The oligopoly solution concept is identified

Einav, L. and J. Levin (201: "Empirical Industrial Organization: A Progress Report." Journal of Economic Perspectives 24 (2):145-162. URL

Grullon, Gustavo, Yelena Larkin, and Roni Michaely(2019): "Are US Industries Becoming More Concentrated?*." Review of Finance 23 (4):697-743. URL

Hall,R.E. (2018): Using Empirical Marginal Cost to Measure Market Power in the US Economy Jean-Fran_cois Houde (2016):Measuring Market Power and Collusion

NEVO, A. (2001): Measuring market power in ready-toeat cereal industry

O’Donnell,C.J., Griffith,G.R., Nightingale,J.J and Piggott,R.R.(2004): Testing for Market Power in Multiple-Input, Multiple-Output Industries: The Australian Grains and Oilseeds industries

Project to replicate cultivation, crop rotation, new varieties, cultivation and diversification of varieties of plant varieties: Feasibility Study (December 2013).

Reiss, P.C. and F.A. Wolak. (2007): "Structural econometric modeling: Rationales and examples from industrial organization." Handbook of econometrics 6:42774415. URL

Resolution of the Government of the Russian Federation of January 27, 2015 N 51
"On approval of the Rules for assigning territories to territories unfavorable for the production of agricultural products"

Resolution No. 70 of the Government of Mongolia of 2008.On "Atar III campaign" national program.

Sadoulet E., A.Janvry (1995) Quantitative Development Policy Analysis

Saini,S. and Gulati,A.(2017): Price distortions in Indian agriculture

Schroeter J.R.(1988): Estimating Degree of Market Power in the Beef Packing Industry 
